\title{
Combined Microwave Radiometer and Micro Rain Radar for Analysis of Cloud Liquid Water
}

\author{
Ha-Young Yang ${ }^{1,3 \dagger}$, Ki-Ho Chang, and Seong-Tae Kang
}

\begin{abstract}
To combine the micro rain radar and microwave radiometer cloud liquid water, we estimate the cloud physical thickness from the difference between the MTSAT-1R cloud top height and cloud base height of visual observation of Daegwallyeong weather station, and the cloud liquid water path of micro rain radar is obtained by multiplying the liquid water content of micro rain radar and the estimated cloud physical thickness. The trend of microwave radiometer liquid water path agrees with that of the micro rain radar during small precipitation. We study these characteristics of micro rain radar and microwave radiometer for small precipitation to obtain the combined cloud water content of micro rain radar and microwave radiometer, constantly operated regardless to the rainfall.
\end{abstract}

Key words: Liquid Water, Micro Rain Radar, Microwave Radiometer

\section{Introduction}

The cloud liquid water is a parameter of vital interest in both modeling and forecasting the weather. But, the cloud is one of the major sources of uncertainty in the model response to its climate forcing ${ }^{[1]}$. Despite its importance, the cloud is represented in a rudimentary way in the climate and weather forecast models because of the lack of knowledge on the variability of its properties. In meso-scale models, the magnitude of latent heat effects corresponds to the amount of cloud liquid water, which is important in the development of a certain weather system. In the observation of the cloud properties, the ground-based microwave radiometry is by far the most accurate method for determining the cloud liquid water path (LWP) compared to the other probing methods like aircraft or cloud Radar observation $^{[2,3]}$. The cloud Radar measurements are affected strongly by the dependency of the reflectivity on the

\footnotetext{
${ }^{1}$ National Institute of Meteorological Research, Korea Meteorological Administration, 6116-gil Yeouidaebang-ro Dongjak-gu Seoul 156-720, Korea

${ }^{2}$ National Typhoon Center, Meteorological Administration, 1622-1 Hannam-ri Namwon-eup Seogwipo-si Jeju 699-948, Korea ${ }^{3}$ Department of Atmospheric Science, Graduate School, Chosun University 309 Pilmun-daero Dong-gu Gwangju 501-759, Korea

†Corresponding author : sttkang@yahoo.co.kr

(Received: February 7, 2013, Revised : March 20, 2013, Accepted: March 25, 2013)
}

drop size distribution. Thus there exists a lack of sufficient, and independent, measurements.

The purpose of this study is to obtain the combined cloud liquid water from ground based microwave radiometer (MWR) and the micro rain radar (MRR), because these two instruments have complementary each other. That is, the LWP observation of the MWR is mainly available in the clear sky condition, while that of the MRR is available in the rainy condition.

\section{Experimental Section}

The cloud liquid water of the two instruments measured at the Cloud Physics Observation System (CPOS) site. The CPOS has been operated from December 2003 at Daegwallyeong (37. 41'N, 128. 45' E and $842 \mathrm{~m}$ from mean sea level) in the Taebaek Mountains to observed and analyzed the characteristics of cloud and precipitation properties ${ }^{[4,5]}$.

\subsection{Microwave Radiometer}

The data used in this study are the radiance, recorded as brightness temperatures, measured with a Radiometerics, Inc., model WVR-1100 microwave radiometer at frequencies of 23.8 and $31.4 \mathrm{GHz}$ and the vertical column amounts of cloud liquid water and water vapor retrieved from these measurements ${ }^{[6]}$. 
Measurements of the sky radiance at the two frequencies, converted to sky brightness temperature, $T b_{v}$ allow the simultaneous determination of precipitable water vapor (PWV) and liquid water path (LWP) from the linear equations,

$$
\begin{aligned}
& P W V=v_{0}+v_{1} \tau_{23.8}+v_{2} \tau_{31.4} \\
& L W P=l_{0}+l_{1} \tau_{23.8}+l_{2} \tau_{31.4}
\end{aligned}
$$

where $\tau_{v}$ is the frequency-dependent total atmospheric optical depth as the sum of the optical depths of water vapor, liquid water and dry air. Basic principles of water vapor and cloud liquid water estimation are described in detail by Güldner and Spänkuch ${ }^{[3]}$.

\subsection{Micro Rain Radar}

The MRR, a vertically pointing FM-CW Doppler radar, is a very useful instrument to measure vertical profiles of precipitation particle size distributions and structures $^{[7]}$. The retrieval of range resolved Doppler spectra follows the method described by Strauch ${ }^{[8]}$. The specification of the MRR installed at the CPOS site is in Table 1. In this study, the height resolution was $150 \mathrm{~m}$ and the time resolution was 1 minute.

The precipitation particle size distribution $(N(D))$ is given.

$$
N(D)=\frac{\eta(D)}{\sigma(D)}
$$

where $D$ is raindrop diameter, $\sigma(D)$ is the back-scattering cross-section, and $\eta(D)$ is the spectral reflectivity as a function of $D$, which is related to $v$, as

$$
\eta(D)=\eta(v) \frac{\delta(v)}{\delta(D)}
$$

where $\eta(v)$ is the spectral volume reflectivity as a function of $v$.

Table 1. The specification of the MRR at the CPOS site.

\begin{tabular}{cc}
\hline Specification & MRR \\
\hline Frequency & $24 \mathrm{GHz}(\mathrm{K}-$ band $)$ \\
Power & $50 \mathrm{~mW}$ \\
Height resolution & $150 \mathrm{~m}$ \\
Average time & $60 \mathrm{~s}$ \\
Height range & $4500 \mathrm{~m}$ \\
Beam width & 1-way, $3 \mathrm{~dB}$ \\
\hline
\end{tabular}

The liquid water content of MRR is defined by the precipitation particle size distribution $N(D)$.

$$
L W C=\rho_{w} \frac{\pi}{6} \int_{0}^{\infty} N(D) D^{3} d D
$$

where $\rho_{w}$ is the density of water.

\subsection{Blending}

To examine the performances of the instruments, the precipitable water vapor (PWV) measured by the MWR was compared with the calculated PWV of the radiosonde soundings at Sokcho (Sokcho, 38 $28^{\prime} \mathrm{N}, 128^{\circ} 52^{\prime} \mathrm{E}$, 17.6 mASL) site from December 2003 to July 2008. The MRR precipitation was compared with those of several Automatic Weather Stations (AWS) near the CPOS.

The PWV of MWR gives good agreement with that of nearest radiosonde soundings: $\mathrm{R}$-square $=0.82$ for spring, 0.78 for summer, 0.83 for fall, but 0.25 for winter (Fig. 1). This bad performance in the winter season seems from the heavy snow on the radome. From this reason, the winter data of MWR have not been considered in the combining algorithm. The comparison of MRR and AWS precipitation shows the correlation coefficient of 30-min accumulated precipitation as Rsquare $=0.84$ (Fig. 2).

To obtain the combined LWP from the MRR and MWR observations, firstly we estimate the cloud phys-
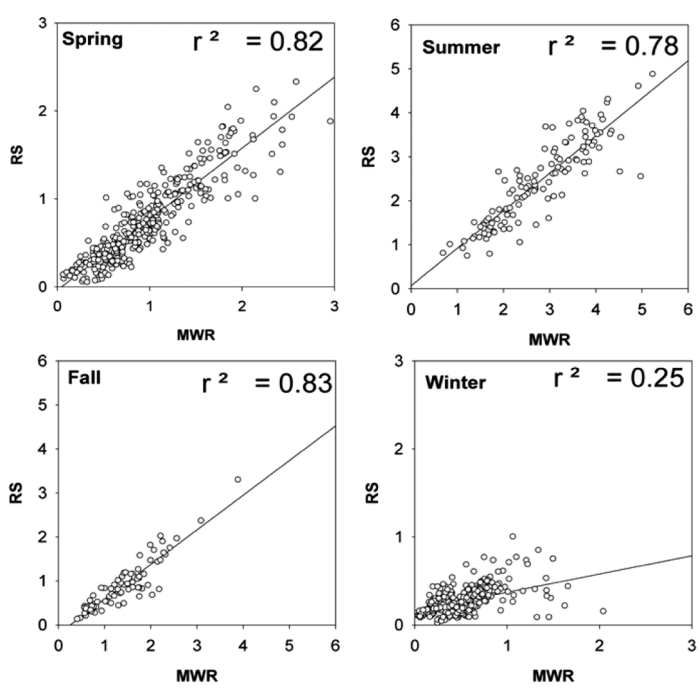

Fig. 1. Comparison of precipitable water vapor measured by the microwave radiometer (MWR) and the radiosonde. 

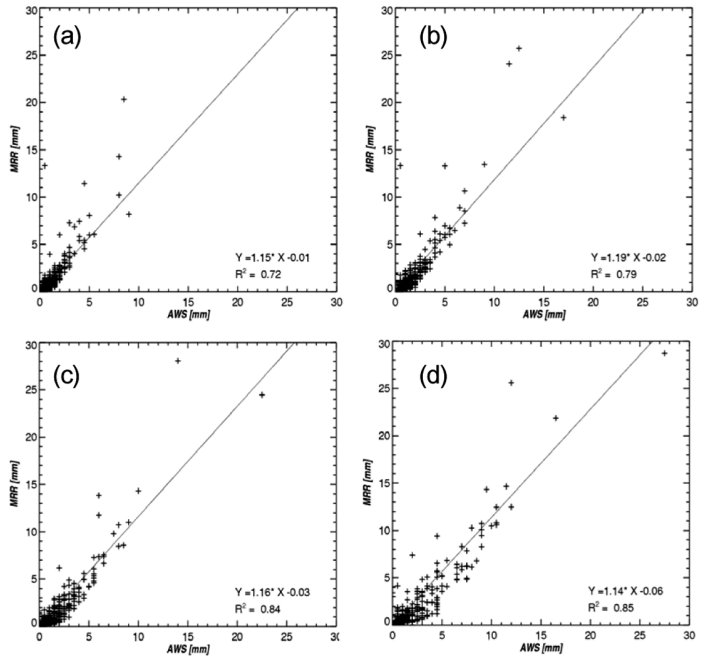

Fig. 2. Comparison of (a) $15 \mathrm{~min}$, (b) $20 \mathrm{~min}$, (c) $30 \mathrm{~min}$, (4) 60 min cumulative rainfall from AWS and MRR.

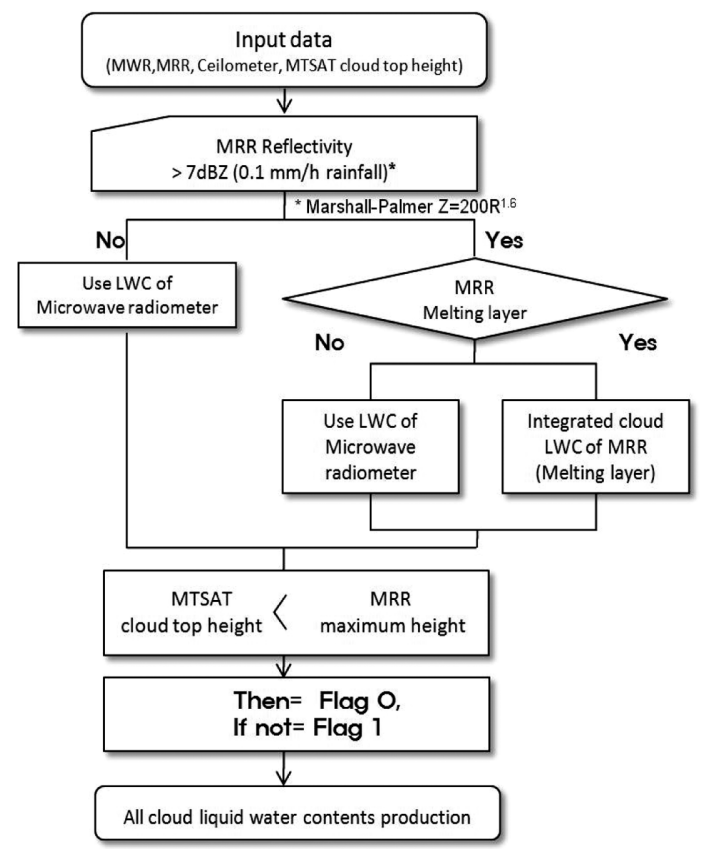

Fig. 3. Flow chart of cloud liquid water contents production.

ical thickness from the difference between the MTSAT$1 \mathrm{R}$ cloud top height and the cloud ceiling observed from the Daegwallyeong Weather Station. The LWP of the MRR is obtained by multiplying the liquid water contents of the MRR to the estimated cloud physical thickness.
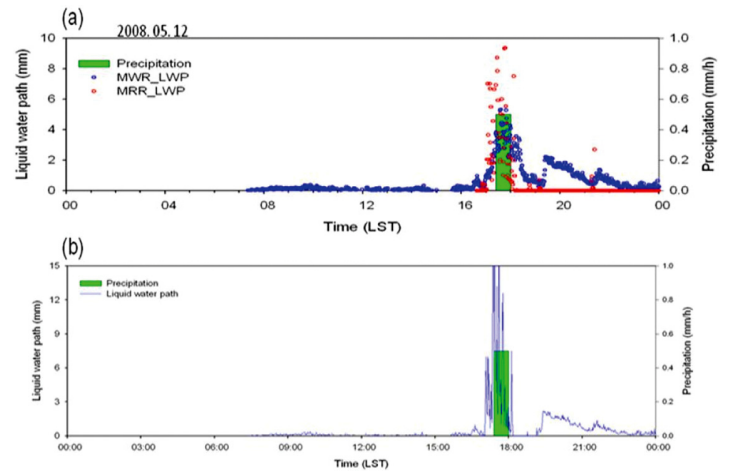

Fig. 4. The time series of the precipitation, the liquid water path from the MWR and MRR (a) and the cloud liquid water combined MRR and MWR (b) on 12 May 2008.

Fig. 3 show flowchart of all cloud liquid water contents production. It is refer Cha's algorithm (2007) for MRR Melting layer ${ }^{[9]}$. If the detected the melting layer in the cloud, use the Liu and Illingworth's formula to calculate the liquid water of $\mathrm{MRR}^{[10]}$.

$$
I W C \text { (Ice Water Contents })=0.097 Z^{0.59}
$$

where $Z$ is the reflectivity of water.

\section{Results and Discussion}

Fig. 4 shows the time series of combined liquid water path on 12 May 2008. The precipitation was $5 \mathrm{~mm}$ between 17 and 18 LST. The LWP of MWR increased during the $30 \mathrm{~min}$ before precipitation and still remained after precipitation. From this result, we presume that it will be useful for the short-term local precipitation forecast. The trend of the MWR liquid water path agrees with that of the MRR during small precipitation.

We will study the characteristics of the MRR and MWR in the small precipitation to obtain the combined cloud water content by constantly operating those instruments regardless of the precipitation.

\section{Acknowledgments}

This study was supported "Advanced Research on Applied Meteorology" of National Institute of Meteorological Research (NIMR) funded by the Korea Meteorological Administration (KMA). 


\section{References}

[1] R. D. Cess, G. L. Potter, J. P. Blanchet, G. J. Boer, A. D. Del Genio, M. Dèquè, V. Dymnikov, V. Galin, W. L. Gates, S. J. Ghan, J. T. Kiehl, A. A. Lacis, H. Le Treut, Z.-X. Li, X.-Z. Liang, B. J. Mcavaney, V. P. Meleshko, J. F. B. Mitchell, J .-J. Morcrette, D. A. Randall, L. Rikus, E. Roeckner, J. F. Royer, U. Schlese, D. A. Sheinin, A. Slingo, A. P. Sokolov, K. E. Taylor, W. M. Washington, R. T. Wetherald, I. Yagai, and M.-H. Zhang, "Intercomparison and interpretation of climate feedback processes in 19 atmospheric general circulation models", J. Geophys. Res., Vol. 95, pp. 16601-16615, 1990.

[2] D. C. Hogg, F. O. Guiraud, J. B. Snider, M. T. Decker, and E. R. Westwater, "A steerable dualchannel microwave radiometer for measurements of water vapor and liquid water in the troposphere", J. Climate Appl. Meteor., Vol. 22, pp. 789-806, 1983.

[3] J. Güldner and D. Spänkuch, "Results of year-round remotely sensed integrated water vapor by groundbased microwave radiometer", J. Appl. Meteor., Vol. 38, pp. 981-988, 1998.

[4] K. H. Chang, S. N. Oh, K. D. Jeong, H. Y. Yang, M. J. Lee, J. Y. Jeong, Y. H. Cho, H. K. Kim, G. M. Park, S. S. Yum, and J. W. Cha, "Cloud physic observation system (CPOS) and validation of its products”, Atmosphere, Vol. 17, pp 101-108, 2007.
[5] Yang, H. Y., J. Y. Jeong, K. H. Chand, J. W. Cha, J. W. Jung, Y. C. Kim, M. J. Lee, Y. Y. Bae, S. Y. Kang, K. L. Kim, Y. J. Choi, and C. Y. Choi, "Intercompatison of Daegwallyeong cloud physics observation system (CPOS) products and the visibility calculation by the FSSP size distribution during 2006-2008", Atmosphere, Vol. 26, pp. 65-73, 2010.

[6] E. Westwater, "The accuracy of water vapor and cloud liquid determination by dual-frequency ground-based microwave radiometry", Radio Sci., Vol. 13, pp. 667-685, 1978.

[7] M. Löffler-Mang and M. Kunz, "On the performance of a low-coat K-band Doppler radar for quantities rain measurements", J. Atmos. Ocean. Technol. Vol. 16, pp. 379-387, 1999.

[8] R. G. Strauch, "Theory and application of the FMCW Doppler radar", Ph. D. Thesis, University of Colorado, p. 97, 1976.

[9] J. W. Cha, S. S. Yum, K.H. Chang, and S. N. Oh, "Estimation of the melting layer from a Micro Rain Radar (MRR) data at the Cloud Physics Observation System (CPOS) site at Daegwallyeong Weather Station”, J. Korean Meteor. Soc., Vol. 43, pp. 77-88, 2007.

[10] C. L. Liu and A. J. Illingworth, "Toward more accurate retrievals of ice water content from radar measurements of clouds", J. Appl. Meteor., Vol. 39, pp. 1130-1146, 2000. 